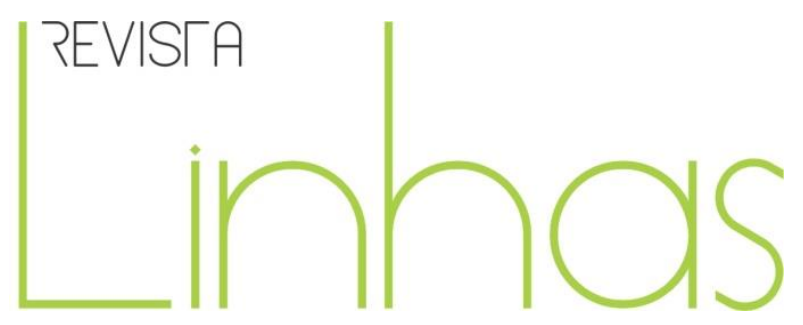

\title{
Avaliação do Programa Social Bolsa Família a partir dos critérios do GesPública: estratégia e planos, processos e pessoas
}

\begin{abstract}
Resumo
O presente artigo visa avaliar o Programa Bolsa Família a partir de critérios estabelecidos através do Programa Nacional de Gestão Pública e Desburocratização (GesPública). Os critérios anteriormente adotados fazem menção às estratégias e planos, processos e pessoas a fim de compreender a estruturalização do programa. A descentralidade empregada na organização do Programa Bolsa Família compartilhada entre as esferas federal, estadual e municipal trabalham em conjunto para aperfeiçoar, ampliar e fiscalizar a execução dos objetivos propostos pelo mesmo. A metodologia empregada vincula-se à estratégia metodológica quadripolar, proposta de De Bruyne, Hermam e Schoutheete (1977); um espaço metodológico quadripolar, no qual o campo científico estrutura-se a partir de uma metodologia geral dividida em quatro polos distintos, mas que interagem entre si enquanto eixos de uma mesma prática metodológica. Este trabalho é uma pesquisa de natureza qualitativa, caracterizando-se como descritiva e exploratória, pois tem como objetivo analisar o Programa Bolsa Família e suas características a partir das informações fornecidas pela gestora municipal do referido programa. A consistência epistemológica para a ciência está no fato de estabelecer a objetividade dos conhecimentos científicos, enquanto elementos intrínsecos à própria ciência. Como resultados obtidos, observa-se que o GesPública promove a governança, aumentando a capacidade de formulação, implementação e avaliação das políticas públicas, além da promoção da gestão democrática, participativa, transparência e ética.
\end{abstract}

Palavras-chave: Administração Pública; Programa Bolsa Família; Política Pública.

\section{Marcos Antonio Martins Lima \\ Universidade Federal do Ceará - UFC - CE/Brasil \\ marcos.a.lima@terra.com.br}

\author{
Jesuína Maria Pereira Ferreira \\ Universidade Federal de Minas \\ Gerais - UFMG - MG/Brasil \\ jesuinna@gmail.com
}

\section{Denize de Melo Silva}

Universidade Federal do Ceará UFC - CE/Brasil

denisemellopedagoga@gmail.com

Liduína Lopes Alves

Universidade Federal do Ceará UFC - CE/Brasil

lidulopes.ufc@gmail.com

\footnotetext{
Para citar este artigo:

LIMA, Marcos Antonio Martins; FERREIRA, Jesuína Maria Pereira; SILVA, Denize de Melo; Alves Liduína Lopes. Avaliação do Programa Social Bolsa Família a partir dos critérios do GesPública: estratégia e planos, processos e pessoas. Revista Linhas. Florianópolis, v. 17, n. 34, p. 337-360, maio/ago. 2016.
} 


\title{
The evaluation of the Social Program Bolsa Família from Gespública criteria: strategy and plans, processes and people
}

\begin{abstract}
This article aims to analyze the Bolsa Família Program based on criteria established by the National Program of Public Management and bureaucratization (GesPública). The criteria previously adopted allude to strategies and plans, processes and people in order to understand the structuralization of the program. The centerlessness employed in the organization of the Bolsa Família Program shared between the federal, state and local levels work together to improve, expand and oversee the implementation of the objectives proposed by the same. The methodology is linked to the methodological strategy quadripolar proposal of De Bruyne, Hermam and Schoutheete (1977), a quadripolar methodological space, in which the scientific field is structured from a general methodology divided into four distinct poles, but interacting as nodes of the same methodological practice. This work is a survey of qualitative nature, characterized as descriptive and exploratory, since it has the aims to analyze the family allowance program and its characteristics from the information provided by the municipal manager of the program. The epistemological consistency to science is in fact establish the objectivity of scientific knowledge, while elements intrinsic to science itself. As results we observe that the GesPública promotes governance by increasing the capacity of the formulation, implementation and evaluation of public policies, and the promotion of democratic, participatory, transparency and ethics.
\end{abstract}

Keywords: Public Administration; Bolsa Família Program; Public Policy. 


\section{Introdução}

Diversos estudos sobre políticas públicas e a questão social têm debatido a eficácia do Programa Bolsa Família, especialmente, com relação a sua nobre missão, ou seja, o combate à pobreza e à desigualdade social, temáticas que passaram a ser prioritárias na agenda governamental a partir de 1990.

O Programa Bolsa Família faz parte dos programas de transferência de renda com condicionalidades, criado no ano de 2003. As condicionalidades do programa são a frequência escolar de 85\% para crianças e adolescentes entre 6 e 15 anos, e de 75\% para adolescentes entre 16 e 17 anos; acompanhamento do calendário vacinal e do crescimento e desenvolvimento para crianças menores de 7 anos; pré-natal das gestantes e acompanhamento das nutrizes; e acompanhamento de ações socioeducativas para crianças em situação de trabalho infantil. Nesse sentido, é possível encontrar na literatura um número razoável de pesquisas relacionadas a condicionalidades do Programa Bolsa Família tais como em Guerra et al (2012), Silva e Monteiro (2012), Fonteles et al (2011); e Moreira, Lima e Lopes (2011).

A gestão do Programa Bolsa Família é descentralizada e compartilhada entre as esferas federal, estadual e municipal, que trabalham em conjunto para aperfeiçoar, ampliar e fiscalizar a execução do Programa. A gestão descentralizada é uma forma de gestão que permite que estas esferas compartilhem entre si os processos de tomadas de decisão do Bolsa Família, criando bases de cooperação para o combate à pobreza e à exclusão social. Essa forma de cooperação está prevista na Constituição Federal.

O desafio é articular os diversos agentes políticos em torno da promoção e inclusão social das famílias beneficiárias. Para isso, deve ser estabelecido um modelo de gestão compartilhada, com competências específicas para cada um dos entes federados.

O Programa Nacional de Gestão Pública e Desburocratização (GesPública) foi instituído em 2005 para desenvolver ações no espaço em que a organização pública se relaciona diretamente com o cidadão. Dentre os diferentes critérios que compõem este programa, foram escolhidos três deles que serão utilizados neste estudo, quais sejam, estratégias e planos, pessoas e processos. 
Nesse sentido, este estudo avaliou o programa Bolsa Família a partir dos critérios do GesPública, uma vez que este programa tem por finalidade contribuir para a melhoria da qualidade dos serviços públicos prestados aos cidadãos e para o aumento da competitividade do País, mantendo-se fiel à ideia de aprimoramento contínuo em busca da excelência em gestão.

O referencial teórico deste estudo trata dos programas Bolsa Família e GesPública, apresentando-os nas bases epistemológica, teórica e morfológica. Esta pesquisa se utilizou da escala Likert de 5 pontos para coleta dos dados. Estes foram tratados por meio do software SPSS. Deste modo, este estudo fez uso da metodologia quadripolar de De Bruyne, Hermam e Schoutheete (1977), que analisa os temas a partir de quatros polos: o epistemológico, o teórico, o morfológico e o técnico.

Este artigo é composto, em seu desenvolvimento, por uma seção sobre a origem e desenvolvimento da gestão pública no Brasil e origem e significado das categorias pessoas, processos e estratégia (polo epistemológico). A seção seguinte trata das teorias da gestão pública e da distribuição de renda (polo teórico). Na terceira seção, apresentam-se os modelos de gestão utilizados neste estudo (polo morfológico) e, em seguida, é demonstrada a análise e o tratamento dos dados (polo técnico).

\section{1 - Polo epistemológico}

O polo epistemológico visa, dentre outros aspectos, a relatar a gênese do objeto, a fim de conceber a realidade dos fatos sob uma nova ótica. "Cabe ao polo epistemológico assegurar a construção do objeto de conhecimento na sua dimensão discursiva" (HÉRBERT-LESSARD; GOYETTE; BOUTIN, 1994, p. 18).

\section{1 - Origem e desenvolvimento da gestão pública no Brasil}

No Brasil, a evolução da administração pública passou por 3 (três) modelos diferentes: a administração patrimonialista, a administração burocrática e a administração gerencial. 
$\mathrm{Na}$ administração pública patrimonialista, própria dos Estados absolutistas europeus do século XVIII, a máquina do Estado é a extensão do próprio poder do governante e os seus funcionários são considerados como membros da nobreza. A corrupção e o nepotismo são traços inerentes a esse tipo de administração.

A administração pública burocrática surge para combater a corrupção e o nepotismo do modelo anterior. São princípios inerentes a este tipo de administração a impessoalidade, o formalismo, a hierarquia funcional, a ideia de carreira pública e a profissionalização do servidor, consubstanciando a ideia de poder racional legal. Existe uma desconfiança prévia dos administradores públicos e dos cidadãos que procuram o Estado com seus pleitos. Os controles administrativos funcionam com o objetivo de evitar a corrupção. A administração burocrática pode correr o risco de transformar o controle em um verdadeiro fim do Estado, e não em um simples meio para atingir seus objetivos. Com isso, a máquina administrativa volta-se para si mesma, perdendo a noção de sua missão básica, que é servir à sociedade.

A administração pública gerencial apresenta-se como uma solução para os problemas da burocracia. Prioriza-se a eficiência da administração, o aumento da qualidade dos serviços e a redução dos custos. Busca-se desenvolver uma cultura gerencial nas organizações, com ênfase nos resultados e no aumento da governança do Estado, isto é, a sua capacidade de gerenciar com efetividade e eficiência. O cidadão passa a ser como peça essencial para o correto desempenho da atividade pública. A administração gerencial constitui um avanço, mas sem romper em definitivo com a administração burocrática, pois não nega todos os seus métodos e princípios.

Evidencia-se uma maior participação da sociedade civil na prestação de serviços que não sejam exclusivos de Estado. São as chamadas entidades paraestatais, que compõem o terceiro setor, composto por entidades da sociedade civil de fins públicos e não lucrativos, como as organizações não governamentais (ONGs), as organizações sociais (OSs) e as organizações da sociedade civil de interesse público (OSCIPs). Este setor passa a coexistir com o primeiro setor, que é o Estado, e com o segundo setor, que é o mercado. Na administração gerencial, a noção de interesse público é diferente da que existe no modelo burocrático. A burocracia vê o interesse público como o interesse do próprio Estado. A administração pública gerencial nega essa visão, identificando este 
interesse com o dos cidadãos, enxergando os integrantes da sociedade como clientes dos serviços públicos.

Atualmente, o modelo gerencial na Administração Pública vem cada vez mais se consolidando, com a mudança de estruturas organizacionais, o estabelecimento de metas a alcançar, a redução da máquina estatal, a descentralização dos serviços públicos, a criação das agências reguladoras para zelar pela adequada prestação dos serviços etc. Este modelo propõe-se a promover o aumento da qualidade e da eficiência dos serviços oferecidos pelo Poder Público aos seus clientes: os cidadãos.

\section{2 - Origem e significado de pessoas, processos e estratégia}

Juntamente com o desenvolvimento e os avanços dos modelos de gestão pública, valem ser destacados os significados da estratégia, processos e pessoas, construtos importantes para o desenvolvimento deste estudo.

A estratégia significava, inicialmente, a ação de comandar ou conduzir exércitos em tempo de guerra - um esforço de guerra (GHEMAWAT, 2000). Representava um meio de vencer o inimigo, um instrumento de vitória na guerra, mais tarde estendido a outros campos do relacionamento humano: político, econômico e ao contexto empresarial, mantendo-se em todos os seus usos a raiz semântica, qual seja, a de estabelecer caminhos (GRAVE; MENDES, 2001).

A palavra processo é derivada do latim processus, significa avanço, marcha e progressão. Método, sistema, modo de fazer uma coisa. Conjunto de manipulações para obter um resultado. $\mathrm{O}$ conjunto dos papéis relativos a um negócio.

Por fim, a palavra pessoa, derivada do latim persona, e possui diferentes significados, o que torna difícil defini-la de uma forma que seja universalmente aceita, devido à sua variabilidade histórica e cultural e às controvérsias que cercam o seu uso nos mais variados contextos. Em geral, pessoa significa ser humano que, por sua vez, é uma entidade que tem certas capacidades ou atributos associados à personalidade em um contexto particular moral, social ou institucional. 


\section{3 - Origem e desenvolvimento da distribuiç̧ão de renda}

Na Grécia Antiga, Platão e Aristóteles já esboçavam seus modelos políticos de gestão pública. Para Platão (428 - 348 a.C.), a dimensão política surge quando se contempla a verdadeira realidade, retornando ao meio dos homens para orientá-los, ensiná-los e dirigi-los. Também acreditavam que as pessoas deveriam ocupar funções diversas na sociedade (CHAUÍ, 2000).

Aristóteles (384 - 322 a.C.) registrou que a política aparece como um prolongamento da moral e estabeleceu três formas de governo: monarquia, aristocracia e politeia. Estabeleceu também que para essas três formas boas existem três formas degeneradas que são a tirania, a oligarquia, e democracia. A boa gestão de uma cidade deve objetivar o interesse comum dos cidadãos e são degeneradas quando possuem interesses particulares (CHAUÍ, 2000).

\section{2 - Polo teórico}

O polo teórico guia a elaboração das hipóteses e a construção dos conceitos. Nesta etapa foram apresentadas e discutidas as teorias para que se forme o quadro referencial pertinente ao estudo.

\section{1 - Conceito e características do Bolsa Família}

Considerado a mais importante ação de assistência, o Bolsa Família é um programa de transferência direta de renda com condicionalidades para as áreas da educação, da saúde e assistência social que devem ser assumidas pelas famílias que desejam e querem continuar a receber o benefício. Tem-se como condicionalidades do programa: frequência escolar de $85 \%$ para crianças e adolescentes entre 6 e 15 anos, e de $75 \%$ para adolescentes entre 16 e 17 anos; acompanhamento do calendário vacinal e do crescimento e desenvolvimento para crianças menores de 7 anos; pré-natal das gestantes e acompanhamento das nutrizes; e acompanhamento de ações socioeducativas para crianças em situação de trabalho infantil. 
O Programa compreende três eixos principais: transferência de renda, condicionalidades e programas complementares. O objetivo da transferência de renda é promover o alívio imediato da pobreza, já as condicionalidades buscam reforçar o acesso a direitos sociais básicos nas áreas de educação, saúde e assistência social; e os programas complementares visam o desenvolvimento das famílias para que os beneficiários consigam superar a situação de vulnerabilidade (BRASIL, 2010).

A gestão do Bolsa Família é descentralizada e compartilhada pela União, estados,

Distrito Federal e municípios. Os três entes federados trabalham em conjunto para aperfeiçoar, ampliar e fiscalizar a execução do Programa.

Os municípios estão encarregados de identificar e inscrever as famílias em situação de pobreza e extrema pobreza no Cadastro Único, gestão dos benefícios do PBF; apurar e/ou o encaminhar as denúncias às instâncias cabíveis; garantir o acesso dos beneficiários do PBF aos serviços de educação e saúde, em articulação com os Governos Federal e Estadual; acompanhar o cumprimento das condicionalidades, em especial atuando nos casos de maior vulnerabilidade social; estabelecer parcerias com órgãos e instituições municipais, estaduais e federais, governamentais e não-governamentais, para a oferta de programas complementares aos beneficiários do Programa Bolsa Família e atualizar informações do Cadastro Único.

Compreende-se que a gestão do Programa Bolsa Família é um conjunto de processos e atividades que visam a garantir a continuidade da transferência de renda às famílias beneficiárias e compreende as atividades de bloqueio, desbloqueio, cancelamento, reversão de cancelamento, suspensão e reversão de suspensão de benefícios, em conformidade com os dispositivos da legislação vigente.

\subsection{Conceito e características do GesPública}

O GesPública tem como missão promover a excelência em gestão pública, visando contribuir para a melhoria da qualidade dos serviços públicos prestados ao cidadão e para o aumento da competitividade do país. A principal estratégia adotada pelo por este programa é a de mobilizar pessoas e organizações voluntárias para a atuarem como agentes transformadores da gestão pública brasileira (GESPÚBLICA, 2010). 


\subsection{1 - Os oito critérios do GesPública}

A Liderança é o critério que examina a governança pública e a governabilidade da organização, incluindo aspectos relativos à transparência, equidade, prestação de contas e responsabilidade corporativa. Também examina como é exercida a liderança, incluindo temas como mudança cultural e implementação do sistema de gestão da organização. $O$ critério aborda a análise do desempenho da organização enfatizando a comparação com o desempenho de outras organizações e a avaliação do êxito das estratégias.

O segundo critério, Estratégias e Planos, examina como a organização, a partir de sua visão de futuro, da análise dos ambientes interno e externo e da sua missão institucional formula suas estratégias, as desdobra em planos de ação de curto e longo prazos e acompanha a sua implementação, visando o atendimento de sua missão e a satisfação das partes interessadas.

O critério Cidadãos examina como a organização, no cumprimento das suas competências institucionais, identifica os cidadãos usuários dos seus serviços e produtos, conhece suas necessidades e avalia a sua capacidade de atendê-las, antecipando-se a elas. Aborda também como ocorre a divulgação de seus serviços, produtos e ações para fortalecer sua imagem institucional e como a organização estreita o relacionamento com seus cidadãos-usuários, medindo a sua satisfação, implementando e promovendo ações de melhoria.

O critério Sociedade avalia como a organização aborda suas responsabilidades perante a sociedade e as comunidades diretamente afetadas pelos seus processos, serviços e produtos e como estimula a cidadania. Examina, também, como a organização atua em relação às políticas públicas do seu setor e como estimula o controle social de suas atividades pela Sociedade e o comportamento ético.

O critério Informações e Conhecimento trata da gestão das informações, incluindo a obtenção de informações comparativas pertinentes. Também examina como a organização identifica, desenvolve, mantém e protege os seus conhecimentos.

O sexto critério, chamado Pessoas, analisa os sistemas de trabalho da organização, incluindo a organização do trabalho, a estrutura de cargos, os processos relativos à seleção e contratação de pessoas, assim como a gestão do desempenho de pessoas e 
equipes. Também examina os processos relativos à capacitação e ao desenvolvimento das pessoas e como a organização promove a qualidade de vida das pessoas interna e externamente ao ambiente de trabalho.

O critério Processos examina como a organização gerencia, analisa e melhora os processos finalísticos e os processos de apoio. Também examina como a organização gerencia o processo de suprimento, destacando o desenvolvimento da sua cadeia de suprimento. O critério aborda como a organização gerencia os seus processos orçamentários e financeiros, visando o seu suporte.

O último critério, de Resultados, examina os resultados da organização, abrangendo os orçamentário-financeiros, os relativos aos cidadãos-usuários, à sociedade, às pessoas, aos processos finalísticos e processos de apoio, assim como os relativos ao suprimento. A avaliação dos resultados inclui a análise da tendência e do nível atual de desempenho, pela verificação do atendimento dos níveis de expectativa das partes interessadas e pela comparação com o desempenho de outras organizações.

\section{3 - Polo morfológico}

O polo morfológico "envolve os métodos de ordenação dos elementos que constituem o objeto científico como as tipologias, os tipos ideais, os sistemas e os modelos estruturais, ao impor a estrutura do objeto científico, que fornece a ordem e as regras para seus elementos" (DE BRUYNE; HERMAM; DE SCHOUTHEETE, 1977, p. 159). Representa a descrição e estudo dos modelos e morfologias que servem de referência para a pesquisa.

\section{1 - Estrutura do Programa Bolsa Família}

O modelo de gestão empregado no Programa Bolsa Família está em consonância com Secretaria Nacional de Renda de Cidadania (SENARC) que tem por objetivo a implementação da Política Nacional de Renda de Cidadania no país. Para garantir a eficácia dessa política, a SENARC faz a gestão do Programa Bolsa Família e do Cadastro Único para Programas Sociais do Governo Federal, promovendo articulação entre ações 
específicas dos programas de transferência de renda federal, estaduais e municipais, estabelecendo a soma de esforços entre os entes federados e as demais ações sociais em curso.

\section{2 - Estrutura do Programa GesPública}

O Modelo de Excelência em Gestão Pública (MEGP) é a referência do GesPública, que busca a excelência na gestão pública com foco em resultados e no cidadão. A aplicação de avaliações comparativas entre as organizações públicas brasileiras e estrangeiras é viabilizada pelo GesPública.

O MEGP deve orientar as organizações na busca da transformação gerencial. Em 1997, o Programa optou pelos critérios de excelência utilizados no Brasil e em diversos países, cujos fundamentos representam o "estado da arte" em gestão. Periodicamente, o Modelo de Excelência em Gestão Pública tem passado por aperfeiçoamentos contínuos com o propósito de acompanhar o "estado da arte" da gestão preconizado pelos modelos de referência que lhe deram origem e de acompanhar também as mudanças havidas na administração pública brasileira.

Acompanhar o "estado da arte" da gestão garante a identidade do modelo com o pensamento contemporâneo sobre excelência em gestão. O Modelo de Excelência em Gestão Pública é a representação de um sistema gerencial constituído de 8 (oito) partes integradas, que orientam a adoção de práticas de excelência com a finalidade de levar as organizações públicas brasileiras a padrões elevados de desempenho e de excelência nesse quesito, conforme o Quadro 1, a seguir.

Este modelo é atualizado e disseminado pelo Programa Nacional de Gestão Pública e Desburocratização (GesPública). 


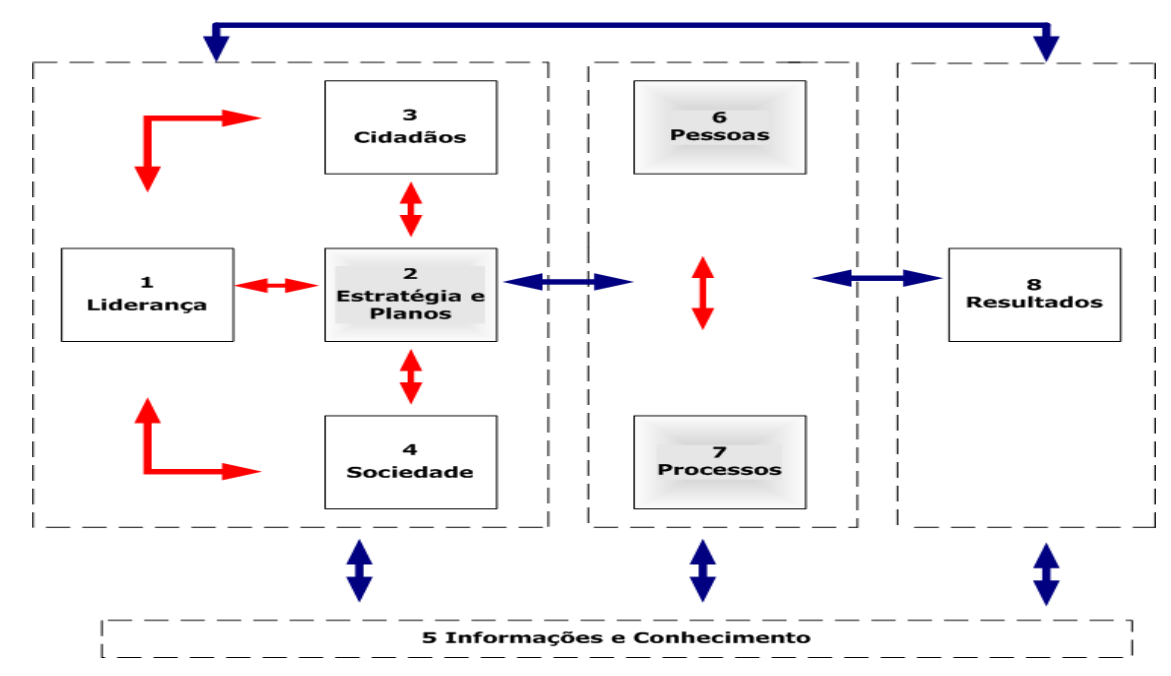

Fonte: GesPública (2008).

Quanto aos critérios do GesPública escolhidos para análise deste estudo, a sua proposta morfológica fica representada de acordo com o Quadro 2, a seguir:

\section{Quadro 2 - Critérios do GesPública para a análise do estudo}

\begin{tabular}{|c|c|}
\hline Critérios & Itens \\
\hline \multirow[t]{2}{*}{ 1. Estratégias e Planos } & 1.1 Formulação das estratégias \\
\hline & 1.2 Implementação das estratégias \\
\hline \multirow{3}{*}{ 2. Pessoas } & 2.1 Sistemas de trabalho \\
\hline & 2.2 Capacitação e desenvolvimento \\
\hline & 2.3 Qualidade de vida \\
\hline \multirow{3}{*}{ 3. Processos } & 3.1 Processos finalísticos e de apoio \\
\hline & 3.2 Processos de suprimento \\
\hline & 3.3 Processos orçamentários e financeiros \\
\hline
\end{tabular}

Fonte: Adaptado do GesPúbllica (2008, p. 26-27). 
O critério Estratégias e Planos se subdivide em formulação e implementação das estratégias. Já o critério Pessoas, tem como itens analisados os sistemas de trabalho, capacitação e desenvolvimento, e qualidade de vida; e por fim, o último critério, Processos, apresenta seus subitens: processos finalísticos e de apoio, processos de suprimento e processos orçamentários e financeiros.

No polo Técnico, a seguir, consta o modelo de pesquisa utilizado no artigo, com base na tríade, estratégia, processos e pessoas em referência ao GesPública.

\section{4 - Polo técnico}

É no polo técnico que se dá o processo de seleção e a construção de operações técnicas de coleta de dados. Este polo exige precisão na sua construção, entretanto, sozinho não garante exatidão, nem significado.

Para sua significação, necessita das explicações conceituais detalhadas no polo teórico e da vigilância reflexiva explicitada pelo eixo epistemológico, assim como da maneira como os modelos são apresentados no polo morfológico, demonstrando uma coerência lógica que articula os fatos científicos numa configuração operativa. (DE BRUYNE; HERMAN; DE SCHOUTHEETE, 1977).

O polo técnico estabelece os procedimentos inerentes à construção da pesquisa. Todavia, constitui-se como fator preponderante para o alcance dos objetivos traçados para a pesquisa e para a geração de novas reflexões por meio das discussões desenvolvidas nessa caminhada epistemológica. O polo técnico controla a coleta de dados, esforça-se por constatá-los para poder confrontá-los com a teoria que os suscitou. Exige precisão na constatação, mas sozinho não garante a sua exatidão. (DE BRUYNE; HERMAN; DE SCHOUTHEETE, 1977).

O revestimento das etapas de construção da pesquisa sedimenta o detalhamento, pois através dessas etapas de investigação e detalhamento, as variáveis são observadas e levadas em consideração para novas proposições de estudo. Portanto, a realidade e o contexto são considerados aspectos formadores no sentido de divergir e convergir epistemologicamente. Conforme o pensamento de De Bruyne, Herman e De Schoutheete 
(1977, p. 201), “o polo técnico trata dos procedimentos de coleta das informações, das transformações destas últimas em dados pertinentes à problemática geral”.

De acordo com Lakatos (2003), a pesquisa compreende um amplo arranjo de questionamentos. As técnicas não reduzem apenas aos direcionamentos incisivos ou resoluções dos questionamentos gerados na pesquisam de forma permanente, entretanto atuam no auxílio como base sólida de saberes e para os meios determinados para uma investigação profunda do objeto em questão oriundo da pesquisa científica.

Todavia, a referida construção relaciona-se à profundidade, caracterizando essa etapa como atenta às proposições supracitadas e regidas à proposta desenvolvida pelo pesquisador. Entretanto, compreender esse processo de construção visa o respeito à diversidade de técnicas e demandas sociais impostas para essa construção metodológica. (BAGNO, 2012).

Portanto, essa construção visa o enquadramento em uma vertente contínua e exploratória, quanto ao seu objetivo geral, e embasa-se na abordagem qualitativa. Adotou-se, pois, o modelo desenvolvido a partir do Programa Nacional de Gestão Pública e Desburocratização (GesPública).

\section{1 - Estratégia metodológica}

A base conceitual gerada a partir das discussões teóricas retratadas reveste-se de sustentação para as técnicas adotadas na pesquisa. Esse olhar reflexivo é inerente ao processo de seleção dos procedimentos e técnicas necessárias para a investigação. Todavia, faz-se importante atentar para a delimitação do objeto e dimensioná-lo para a sedimentação de novas bases de conhecimento e métodos empregados na pesquisa (MINAYO, 2013).

Ratificando o pensamento do autor, verifica-se que esse caminhar repleto de métodos e técnicas, com base na realidade empreendida, é reduzido ou mal compreendido, o que acarreta o uso de mecanismos vazios de sentido para o aprofundamento da investigação.

Necessita-se observar os caminhos que regem o conhecimento e torná-lo acessível, dialogando com as bases teóricas anteriormente formuladas. O instrumento adotado na pesquisa constitui-se como questionário fechado e estruturado a partir do 
referencial teórico adotado com o intuito de guiar e gerar novas proposições acerca da avaliação da gestão a ser empreendida nas instituições de ensino pesquisadas.

O mapeamento das estruturas (critérios) foi amparado no modelo de excelência denominado GesPública e os critérios adotados a partir da análise dos agentes impulsionadores que regem a gestão eficiente e as práticas adotadas para resultados positivos. Elencou-se 3 (três) critérios para subsidiar a feitura do instrumental da pesquisa, nesse caso, o questionário semiestruturado, foi composto por 2 (duas) seções denominadas A e B.

Na seção A, procurou-se traçar o perfil dos respondentes da pesquisa, objetivando a caracterização e enquadramento na respectiva instituição atuante no setor e organização do Programa Bolsa Família. Na seção B, pretendeu-se, a partir do referencial teórico estruturado durante a feitura da pesquisa, elencar 18 (dezoito) indicadores sedimentados por meio do GesPública.

Diante disso, buscou-se elencar os 3 (três) dos 8 (oito) critérios do programa de excelência denominado GesPública: estratégia e planos, processos e pessoas e, a partir desse movimento, evidenciar a organização do Programa Bolsa Família com base na tríade supracitada. Portanto, essa ação visa à análise acerca das contribuições do respectivo modelo para a sistematização das ações realizadas nas instituições.

O questionário semiestruturado a partir dos critérios explanados nessa construção foi aplicado em 2012, na gestão municipal do Programa Bolsa Família, localizado na Secretária da Ação Social no estado do Ceará. Para Demo (2000), esse processo visa à contextualização das ações que são desempenhadas pelos sujeitos participantes dessa construção.

Diante desse contexto, as estratégias adotadas para a pesquisa devem ser compostas por “daquilo que é e daquilo que deve ser" (WEBER, 2001, p. 81); todavia, fazse importante considerar os aspectos que regem a construção progressiva do conhecimento nas ciências sociais. A escala de percepção adotada na feitura do instrumental atrela-se conforme quadro 3 (três), e visa o estabelecimento do nível de compreensão dos gestores acerca das afirmativas contidas nessa construção. 
Quadro 3 - Escala de percepção Likert adotada na pesquisa

\begin{tabular}{|c|l|}
\hline \multicolumn{1}{|c|}{ Escala } & \multicolumn{1}{c|}{ Afirmativas } \\
\hline 0 & Práticas inadequadas ou inexistentes. \\
\hline 1 & Práticas parcialmente adequadas, uso esporádico. \\
\hline 2 & $\begin{array}{l}\text { Práticas parcialmente adequadas, em início de } \\
\text { implementação. }\end{array}$ \\
\hline 3 & Práticas adequadas, em início de implementação. \\
\hline 4 & $\begin{array}{l}\text { Práticas adequadas, disseminadas em muitas áreas e } \\
\text { de uso contínuo. }\end{array}$ \\
\hline
\end{tabular}

Fonte: Adaptado de Bonini e Bonini (1972).

Esse viés fomenta alinhamentos para os achados da pesquisa, estabelecendo impressões e vivências construídas da experiência do pesquisador por meio do conhecimento obtido através do campo. Tais procedimentos estão vinculados a essa busca constante de ampliação da atividade de pesquisa (MINAYO, 2013).

Este trabalho trata de estudo descritivo exploratório, com abordagem metodológica do tipo qualitativa. Caracterizando-se como descritiva, pois tem como objetivo analisar o Programa Bolsa Família e suas características a partir das informações dos gestores municipais do referido programa.

Minayo (2004 p. 51) aponta as metodologias qualitativas como: “[...] aquelas capazes de incorporar a questão do significado e da intencionalidade como inerentes aos atos, às relações, e às estruturas sociais, sendo essas últimas tomadas tanto no seu advento quanto na sua transformação, como construções humanas significativas”.

\section{5 - Resultados e discussão}

Sabe-se que o Gespública auxilia na prática de ações e tomadas de decisões para o pleno funcionamento do Programa Bolsa Família. Diante disso, questionou-se a gestora do Programa Bolsa Família proveniente do município de Fortaleza-CE, acerca dos direcionamentos realizados no programa e se os mesmos estão em consonância com os critérios preconizados pelo Gespública. Os critérios estabelecidos para a análise 
contemplada na construção teórica construída anteriormente são estratégias e planos, processos e pessoas.

Neste contexto, cabe observar os fundamentos que integram a gestão pública, desse modo, os valores, normas e técnicas necessitam ser internalizados pelos sujeitos que compõem a esfera pública.

O instrumento de pesquisa (questionário) aplicado junto à gestora do Programa Bolsa Família, em sua seção inicial, permitiu levantar dados sobre o perfil da instituição: nome, sigla, cargo da respondente e o tempo de atuação no programa.

Verificou-se, conforme a análise da respectiva seção, que a gestora do programa atua na Secretaria do Trabalho e Desenvolvimento Social (STDS), enquadramento estadual e atua como coordenadora de projetos na respectiva instituição. Atua nessa função por um período de 3 (três) a 6 (seis) anos.

$\mathrm{Na}$ seção seguinte ao questionário aplicado na pesquisa, foram construídos 6 (seis) indicadores com base no critério Estratégias e Planos preconizados pelo Programa de Gestão Pública e Desburocratização (Gespública). Esse critério examina a organização a partir de sua visão de futuro, da análise dos ambientes interno e externo e da sua missão institucional, formulando suas estratégias e planos de ação de curto e longo prazos.

Observou-se que a gestora considera que o Programa Bolsa Família agrega aspectos relativos ao ambiente externo para formulação das suas estratégias, tais como relacionamento com outros órgãos e entidades para formar parcerias, sendo essas práticas concebidas como contínuas no tocante ao desenvolvimento do respectivo programa.

A respondente preconiza as estratégias aliadas aos objetivos da organização que se insere no desenvolvimento sustentável, buscando o atingir metas favoráveis nas áreas sociais, ambiental e econômica.

De acordo a gestora consultada, são estabelecidas metas de curto e longo prazo, definidos pelos respectivos planos de ação, com o intuito de reduzir custos e alcançar as metas e estratégias propostas pelo programa. Cada área do Programa Bolsa família estabelece metas e estratégias a fim de cumprir os ideais do programa. 
Conforme a análise, a gestora enfatiza a comunicação vinculada às metas e revelada através de indicadores e planos de ação realizados, segundo a mesma, de forma eficiente, existindo, pois, um constante monitoramento para a implementação de planos no programa.

O critério Pessoas foi avaliado conforme a escala de percepção adotada e constatou-se que este critério visa examinar os sistemas de trabalho da organização, incluindo a organização do trabalho, a estrutura dos cargos, os processos relativos à seleção e à contratação de pessoas, assim como a gestão do desempenho de pessoas e equipes. Também examina os processos relativos à capacitação e ao desenvolvimento das pessoas com o intuito de promoção da qualidade de vida, quando da sua inserção no ambiente de trabalho.

\section{Quadro 4 - Análise do critério Pessoas conforme a gestora do Programa Bolsa Família}

\begin{tabular}{|c|c|}
\hline Indicadores de Avaliação & Escala de Percepção \\
\hline $\begin{array}{l}\text { Os colaboradores/funcionários que atuam no } \\
\text { Programa Bolsa Família têm grau de autonomia } \\
\text { para definir, gerir e melhorar os processos com } \\
\text { flexibilidade e rapidez visando os interesses dos } \\
\text { cidadãos. }\end{array}$ & $\begin{array}{l}\text { Práticas Parcialmente adequadas, em início de } \\
\text { implementação. }\end{array}$ \\
\hline $\begin{array}{l}\text { Há mecanismos/veículos que asseguram a } \\
\text { comunicação eficaz entre as áreas da organização. }\end{array}$ & $\begin{array}{l}\text { Práticas adequadas, disseminadas a muitas áreas e } \\
\text { de uso contínuo. }\end{array}$ \\
\hline $\begin{array}{l}\text { O sistema de remuneração, de reconhecimento e } \\
\text { de incentivos para as pessoas estimula o alcance de } \\
\text { metas de alto desempenho, do aprendizado e da } \\
\text { cultura da excelência. }\end{array}$ & Práticas parcialmente adequadas, uso esporádico. \\
\hline $\begin{array}{l}\text { Os programas de capacitação e desenvolvimento } \\
\text { abordam a cultura da excelência e contribuem para } \\
\text { consolidar o aprendizado organizacional. }\end{array}$ & Práticas adequadas, em início de implementação. \\
\hline $\begin{array}{l}\text { Os fatores que afetam o bem-estar, a satisfação e a } \\
\text { motivação das pessoas são levados em } \\
\text { consideração a fim de manter um clima } \\
\text { organizacional favorável ao alto desempenho, } \\
\text { considerando os diferentes grupos de pessoas. }\end{array}$ & Práticas inadequadas ou inexistentes. \\
\hline $\begin{array}{l}\text { São colocados à disposição dos } \\
\text { colaboradores/funcionários serviços, benefícios, } \\
\text { programas e políticas relacionadas à qualidade de } \\
\text { vida no trabalho. }\end{array}$ & Práticas inadequadas ou inexistentes. \\
\hline
\end{tabular}

Fonte: Da pesquisa. 
Verificou-se conforme a análise dos indicadores que o respectivo critério se encontra em fase de consolidação. Os serviços relacionados à qualidade de vida dos colaboradores são práticas consideradas inexistentes no tocante a organização do Programa Bolsa Família no município de Fortaleza-CE.

Conforme o indicador presente no instrumental embasado no GesPública, os colaboradores que atuam no Programa Bolsa Família têm grau de autonomia para definir, gerir e melhorar os processos com flexibilidade e rapidez visando os interesses dos cidadãos. A gestora do respectivo programa classificou esse processo como parcialmente adequado ao programa, sendo que essas alternativas usadas ainda não ocasionam autonomia e flexibilidade aos colaboradores.

Segundo ela, existem mecanismos que asseguram a comunicação eficaz entre as áreas da organização do programa, entretanto, o sistema não oferece remuneração, reconhecimento e incentivos para as pessoas, pois não estipulam o alcance de metas de alto desempenho, do aprendizado e cultura de excelência aos seus integrantes.

$\mathrm{Na}$ avaliação relativa ao critério Processos, evidenciam-se os procedimentos de organização para a melhoria dos processos finalísticos e de apoio. Esse gerenciamento visa o destaque para o desenvolvimento de suprimentos orçamentários e financeiros objetivando o suporte ao Programa Bolsa Família. Em face disso, o quadro 5 (cinco) abaixo remete à compreensão da gestora pesquisada na observância dos indicadores embasados nesse critério. 


\begin{tabular}{|c|c|}
\hline Indicadores de Avaliação & Escala de Percepção \\
\hline $\begin{array}{l}\text { Percebe-se que as necessidades dos cidadãos- } \\
\text { usuários e da sociedade são traduzidas em } \\
\text { requisitos e incorporadas aos projetos de serviços } \\
\text { ou produtos, e aos processos finalísticos. }\end{array}$ & $\begin{array}{l}\text { Práticas adequadas, disseminadas a muitas áreas e } \\
\text { de uso contínuo. }\end{array}$ \\
\hline $\begin{array}{l}\text { O programa se utiliza de metodologias para } \\
\text { aumentar a confiabilidade dos produtos ou serviços } \\
\text { fornecidos pela organização. }\end{array}$ & $\begin{array}{l}\text { Práticas adequadas, disseminadas a muitas áreas e } \\
\text { de uso contínuo. }\end{array}$ \\
\hline $\begin{array}{l}\text { É realizada a identificação dos potenciais } \\
\text { fornecedores e o desenvolvimento da cadeia de } \\
\text { suprimentos que visam assegurar a disponibilidade } \\
\text { de fornecimento em longo prazo, melhorar o seu } \\
\text { desempenho e o desenvolvimento sustentável da } \\
\text { própria cadeia. }\end{array}$ & $\begin{array}{l}\text { Práticas adequadas, disseminadas a muitas áreas e } \\
\text { de uso contínuo. }\end{array}$ \\
\hline $\begin{array}{l}\text { O processo de aquisição de bens, de materiais e de } \\
\text { serviços é realizado de forma a assegurar a } \\
\text { transparência, o atendimento à legislação e os } \\
\text { aspectos relativos à segurança, à saúde e ao meio } \\
\text { ambiente. }\end{array}$ & $\begin{array}{l}\text { Práticas adequadas, disseminadas a muitas áreas e } \\
\text { de uso contínuo. }\end{array}$ \\
\hline $\begin{array}{l}\text { A proposta orçamentária analisa as restrições e } \\
\text { liberações de orçamento mais significativas que } \\
\text { possam vir a afetar a execução das atividades do } \\
\text { programa. }\end{array}$ & Práticas adequadas, em início de implementação. \\
\hline $\begin{array}{l}\text { Os processos orçamentários e financeiros são } \\
\text { gerenciados para suportar as necessidades } \\
\text { estratégicas e operacionais do programa. }\end{array}$ & Práticas adequadas, em início de implementação. \\
\hline
\end{tabular}

Fonte: Da pesquisa.

Conforme os indicadores presentes no instrumental, não se observam propostas orçamentárias significativas que afetem a execução das atividades exercidas pelo programa. Os processos gerenciais e financeiros não são vinculados às necessidades estratégicas observadas na operacionalização do Programa Bolsa Família. A partir da análise realizada, percebeu-se que as necessidades dos cidadãos e da sociedade são reproduzidas em requisitos e incorporadas aos projetos de serviços ou produtos, bem como aos processos finalísticos.

Em face do exposto, a gestora corrobora que desde julho de 2012 a agosto de 2013, foram 1.281 (um mil e duzentos e oitenta e um) atores sociais, estaduais e municipais responsáveis pela implementação e gestão das condicionalidades do Programa Bolsa Família.

Segundo a respondente, apesar da mudança elevada de mais de 70\% de prefeitos, impactando na substituição de secretários e na rotatividade dos técnicos municipais no 
estado do Ceará, o Índice de Gestão Descentralizada Estadual - IGDE aumentou de 0,86, de julho/2012, para 0,88, no $1^{\circ}$ semestre de 2013. A taxa de acompanhamento da frequência escolar que era de 0,89 passou para 0,91 e, a da saúde, de 0,76 para 0,79\%.

Foi realizada a avaliação das ações executadas no ano de 2012 e compartilhadas entre as áreas da assistência social, educação e saúde; bem como foi elaborado o planejamento e realizado o acompanhamento das ações do primeiro semestre do ano de 2013 com a maior participação das três áreas responsáveis pelas condicionalidades.

Ocorreu a produção e o compartilhamento de conhecimento e experiências exitosas das três áreas, fortalecendo a Rede Intersetorial dos Atores Sociais do Cadastro Único e do Programa Bolsa Família.

\section{6 - Considerações finais}

Este estudo teve como objetivo avaliar o programa Bolsa Família a partir de três critérios do GesPública: estratégias e planos, processos e pessoas.

O principal achado da análise do Programa Bolsa Família configura-se pelo viés compensatório e que após a Constituição de 1988 - quando houve um pacto social - o governo Lula vinculou suas ações ao setor econômico em detrimento do social. Assim, pode-se perceber que o referido programa possui um caráter minimalista, focalista, setorialista e de solução imediata consonante com a ideologia neoliberal.

Comparando os resultados com outras pesquisas sobre o programa Bolsa Família, o acompanhamento do cumprimento das condicionalidades é delegado ao Ministério do Desenvolvimento Social (MDS), juntamente com o Ministério da Educação (MEC) e o Ministério da Saúde (MS), através de uma gestão descentralizada, encarregando a fiscalização também para cada município.

Contudo, o máximo que isso pode proporcionar é a melhoria da qualidade de vida e o afastamento das crianças das ruas, porém não temos uma análise do aproveitamento pedagógico dos educandos envolvidos no processo educativo, pois a frequência é o único instrumento adotado como controle para a obtenção do benefício. 
Observa-se que o GesPública contribui para uma melhor compreensão acerca dos fatores de desenvolvimento e gestão do programa enquanto política educacional, pois possibilita novos encaminhamentos para a promoção dos resultados preconizados pelo programa.

Analisa-se que o GesPública promove a governança, aumentando a capacidade de formulação, implementação e avaliação das políticas públicas, além da promoção da gestão democrática, participativa, transparente e ética.

\section{Referências}

BAGNO, Marcos. Pesquisa na escola: o que é, como se faz? São Paulo: Edições Loyola, 2012.

BONINI, Edmundo Eboli; BONINI, Sergio Eboli. Teoria e exercícios de estatística. São Paulo: Livraria Nobel, 1972.

BRASIL. Programa Nacional de Gestão Pública e Desburocratização. Brasília, 2008.

BRASIL. Fome Zero. Brasília, 2010. Disponível em: Disponível em:

<http://www.fomezero.gov.br/artigo/bolsa-familia-quem-paga-quem-recebe-e-para-quelucia-modesto>. Acesso em: 21 de novembro de 2011.

BRASIL. Fundo Nacional de Desenvolvimento da Educação. Brasília, 2013. Disponível em: <http://www.fnde.gov.br/>. Acesso em: 21 de novembro de 2011. 
BRASIL. Ministério do Desenvolvimento Social e Combate a Fome. Secretaria de Avaliação e Gestão da Informação. Matriz de informação social. Curitiba, 2009. Disponível em: <http://aplicacoes.mds.gov.br/sagi/mi2007/home/login.php>. Acesso em: 18 de fevereiro de 2010.

BRASIL. Ministério do Desenvolvimento Social e Combate a Fome. A gestão do programa. Brasília, 2011. Disponível em: <http://www.mds.gov.br/bolsafamilia>. Acesso em: 21 de novembro de 2011.

BRASIL. Ministério do Planejamento, Orçamento e Gestão. Relatório da Avaliação da Gestão Hospital Geral do Recife. Brasília: Ministério Público, GESPÚBLICA, 2006.

BRASIL. Ministério do Planejamento, Orçamento e Gestão. Programa da Qualidade no Serviço Público: Instrumento de avaliação da gestão pública Ciclo 2008-2009. Brasília, Distrito Federal, 2008.

COSTA, Frederico Lustosa da. Brasil: 200 anos de Estado; 200 anos de administração pública; 200 anos de reformas. Rev. Adm. Pública, Rio de Janeiro, v.42, n.5, 2008.

CHAUÍ, Marilena. Convite à filosofia. $9^{\text {a }}$ edição. São Paulo: Ática, 2000.

DEMO, Pedro. Avaliação sob o olhar propedêutico. Campinas, SP: Papirus, 2000.

DE BRUYNE, Paul; HERMAN, Jacques; DE SCHOUTHEETE, Marc. Dinâmica da Pesquisa em Ciências Sociais: os pólos da prática metodológica. Prefácio de Jean Ladrière. Tradução de Ruth Joffily. Rio de Janeiro: Livraria Francisco Alves Editora, 1977.

FONTELES, Auridete L. et al. Programa Bolsa Família e mobilidade social: sociabilização, trabalho e educação nas famílias beneficiadas. In: Encontro da Associação dos Programas de Pós-Graduação em Administração, 35², Rio de Janeiro, 2011.

GESPÚBLICA. Programa Nacional de Gestão Pública e Desburocratização. Brasília, 2010. Disponível em: http://www.gespublica.gov.br/autores/secretaria-de-gest\%C3\%A3omp. Acesso em: 19 de Janeiro de 2010.

GHEMAWAT, Pankaj. A estratégia e o cenário dos negócios: texto e casos. Porto Alegre: Bookman, 2000.

GRAVE, Paulo; MENDES, Ariston. Pensamento estratégico contemporâneo: possíveis fundamentos antigos da estratégia como uma medida administrativa atual ou em busca ao elo perdido? In: Encontro da Associação dos Programas de Pós-Graduação em Administração, $25^{\circ}$, Campinas, set. 2001. Anais... Campinas: ANPAD, 2001. 15 p.

GUERRA, Ana et al. Programa Bolsa Família: uma análise sob o ponto de vista dos usuários. In: Encontro da Associação dos Programas de Pós-Graduação em Administração, $36^{\circ}$, Anais... Rio de Janeiro: ANPAD, 2012. Disponível em: 
<www.anpad.org.br/evento.php?acao=trabalho\&cod_edicao_subsecao=848\&cod_event o_edicao=63\&cod_edicao_trabalho=14415>. Acesso em: 14 de junho de 2013 .

HÉRBERT-LESSARD, Michellé; GOYETTE, Gabriel; BOUTIN,Gérard. Investigação qualitativa: fundamentos e práticas. Lisboa: Instituto Piaget, 1990.

LAKATOS, Eva Maria. Fundamentos da metodologia científica. São Paulo: Editora Atlas, 2003.

MINAYO, Maria Cecília de Souza. 0 desafio do conhecimento: pesquisa qualitativa em saúde. 8.ed. São Paulo: Hucitec, 2004.

MINAYO, Maria Cecília de Souza. Pesquisa social: teoria, método e criatividade.

Petrópolis, RJ: Vozes, 2013.

MOREIRA, Nathalia; LIMA, Afonso; LOPES, Maria. Dimensões do Empoderamento das Mulheres Beneficiárias do Programa Bolsa Família. In: Encontro da Associação dos

Programas de Pós-Graduação em Administração, 35², Rio de Janeiro, 2011.

SILVA, Ambrozina de Abreu Pereira; FERREIRA, Marco Aurélio Marques; MONTEIRO, Doraliza Abranches. Desempenho na gestão pública do Programa Bolsa Família sob a perspectiva de análise do Índice de Gestão Descentralizada (IGD). Rev. Desenvolvimento em Questão, Editora Unijuí, v. 10, n. 21, p. 211-241, set./dez, 2012.

WEBER, Max. Metodologia das ciências sociais. São Paulo: Editora Cortez, 2001.

Recebido em: 07/09/2014 Aprovado em: 18/04/2016

Universidade do Estado de Santa Catarina - UDESC Programa de Pós-Graduação em Educação - PPGE Revista Linhas

Volume 17 - Número 34 - Ano 2016 revistalinhas@gmail.com 